ARTICLE HISTORY: Received: October 20, 2021 Accepted: December 11, 2021 Published: December 19, 2021

\title{
THE PROBLEM OF INTERDISCIPLINARY INTEGRATION OF PHYSICS AND MATHEMATICS IN A HIGH SCHOOL
}

\author{
Dehqonova Ohista Kosimjonovna \\ Teacher, \\ Fergana State University, Fergana, Uzbekistan \\ Kholbo'taev Sherzod \\ Teacher, \\ Jizzakh State Pedagogical Institute, Jizzakh, Uzbekistan \\ Sh.Rashidov-4, 130100, Jizzax, Uzbekistan \\ Xotamov Jahongir \\ Teacher, \\ Jizzakh State Pedagogical Institute, Jizzakh, Uzbekistan \\ Sh.Rashidov-4, 130100, Jizzax, Uzbekistan
}

\begin{abstract}
The paper is devoted to study the problem of interdisciplinary integration of physics and mathematics in educational system. It was shown that interdisciplinary integration is presented as a means of increasing students' independent creative abilities, increasing and shaping their worldview and scientific thinking, ultimately improving the entire educational process.
\end{abstract}

Key words: Interdisciplinary integration, physics, chemistry, mathematics.

Introduction. The problem of interdisciplinary integration is one of the main problems of pedagogy, which contributes to the comprehensive development of the general worldview of future specialists, will improve the quality of scientific knowledge, the systematic mobility of education. In the elementary grades, students will be able to use everything from simple homogeneous equations to quadratic equations in solving physical problems. Students do a lot of measurement work while experimenting in lab classes. In order to easily master the topic, students must first know the concepts of length, surface, ratio, percentage in mathematics. For example, in the 7th grade physics course of secondary schools, mathematical concepts such as percentage, projection, inverse proportion, combinatorial elements, surface and volume are widely used in conducting laboratory classes on Archimedes' laws.

The interconnection of physics and mathematics is manifested in the definition of certain physical quantities, as well as in the mathematical expressions of physical laws. When we talk about physical measurements like length, surface, volume, mass, temperature, path, time, it is first carefully studied and refined. Measurement of physical quantities, determination of units of measure is carried out by performing mathematical operations. For example, in a course in electrodynamics, electric and magnetic fields are described by a lot and complex mathematical formulas. This course contains not only differential and integral actions, but also such actions as divergence or rotor, etc. This indicates a connection between two disciplines - mathematics and physics.

The scientific results. 1. In the mechanics section of a physics course, you have to use different mathematical functions and their graphs to solve problems. For example, one of these is the simplest linear function.

A straight line is a road in straight motion. Knowing the velocity of a material point in a straight line, it is possible to calculate the path it has traversed in a given time. Vector expression of displacement

$$
\Delta \overrightarrow{\mathrm{s}}=\overrightarrow{\mathrm{s}}-\overrightarrow{\mathrm{s}}_{0}=\overrightarrow{\mathrm{v}} \cdot\left(\mathrm{t}-\mathrm{t}_{0}\right) .
$$

The formula for calculating the path for the length of the displacement vector in a straight line is equal to the distance traveled

$$
\Delta \mathrm{s}=\mathrm{s}-\mathrm{s}_{0}=\mathrm{v} \cdot\left(\mathrm{t}-\mathrm{t}_{0}\right) .
$$

The path taken by an object at any time $t$ is based on (2)

$$
\mathrm{s}=\mathrm{s}_{0}+\mathrm{v} \cdot\left(\mathrm{t}-\mathrm{t}_{0}\right),
$$


formula

is calculated using the formula. It can be taken as a counting head in the study of motion. In that case the migration

$$
\overrightarrow{\mathrm{s}}=\overrightarrow{\mathrm{s}}_{0}+\overrightarrow{\mathrm{v}} \cdot \mathrm{t} \text {, }
$$

appears. The last formula is called the equation of motion of a material point. For example, the equation of motion of an object with initial position $\mathrm{s}_{0}=5 \mathrm{~m}$ and velocity $\mathrm{v}=2 \mathrm{~m} / \mathrm{s}$ is given by (4).

\begin{tabular}{|c|c|c|c|c|c|c|c|c|}
\hline $\mathrm{T}, \mathrm{s}$ & 0 & 1 & 2 & 3 & 4 & 5 & 6 & 7 \\
\hline $\mathrm{s}=5+2 \mathrm{t}, \mathrm{m}$ & 5 & 7 & 9 & 11 & 13 & 15 & 17 & 19 \\
\hline
\end{tabular}

In solving problems of physics, we encounter parabolic functions in addition to the functions listed above. For example, in the mechanics section of physics subject, the motion of a body to fall freely in a gravitational field, and in the work and energy section, the kinetic energy formulas are represented by parabolic functions (Table 2 ).

Table 2.

\begin{tabular}{|c|c|}
\hline Physical functional connections & Mathematical functions \\
\hline $\mathrm{h}=\mathrm{g} \frac{\mathrm{t}^{2}}{2}$ & $\mathrm{y}=\mathrm{a} \frac{\mathrm{x}^{2}}{2}$ \\
$\mathrm{E}=\mathrm{m} \frac{\mathrm{v}^{2}}{2}$ & \\
\hline
\end{tabular}

To fully understand the essence of a physical phenomenon, of course, it is better to use its graphs of parabolic function according to the last table.

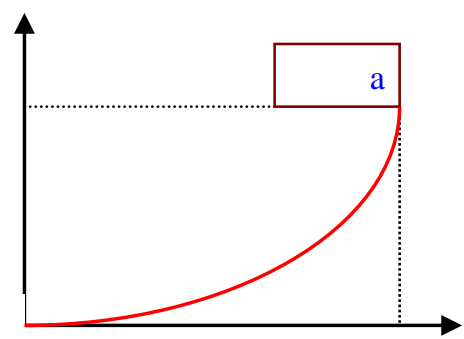

Figure. The graphic of parabolic function

For example, in mathematics, a graph of a simple parabolic function can be thought of as in Figure/ In this case, it is possible to create a graph of the given function by compiling a table, knowing the field of definition of the quantities involved in the equation, the field of values. Once the reader has analyzed the laws of change of this given function, this knowledge can be easily applied to physical problems.

Conclusuon. In conclusion, we believe that the use of basic concepts and formulas of mathematics in the teaching of physics in secondary schools, especially in laboratory classes and problem solving, plays a very important role in developing students' ability to quickly and easily analyze topics.

\section{References}

1. Park, D., O'Brien, G., Eraso, M., \& McClintock, E. (2002). A Scooter Inquiry: An Integrated Science, Mathematics, and Technology Activity.Science Activities, 39(3), 27-32p.

2. Heller, M. (1997). Essential tension: Mathematics-physics-philosophy. Foundations of Science, 2(1), 39-52p.

3. Hudson, H. T., \& McIntire, W. R. (1977). Correlation between mathematical skills and success in physics. American Journal of Physics, 45(5), 470-471p. 
4. Kapucu, S. (2014a). University students' conceptions of the relationship between mathematics and physics and the relationship between mathematics and physics learning. Journal of Baltic Science Education, 13(5), 622-636p.

5. Korsunsky, B. (2002). Improper use of physics-related context in high school mathematics problems: Implications for learning and teaching. School Science and Mathematics, 102(3), 107-113p.

6. Martinez-Torregrosa, J., Lopez-Gay, R., \& Gras-Marti, A. (2006). Mathematics in physics education: Scanning historical evolution of the differential to find a more appropriate model for teaching differential calculus in physics. Science \& Education, 15(5), 447-462p. 